\title{
Differences in kinematics of the support limb depends on specific movement tasks of take-off
}

\author{
Vladimír Hojka*, Radka Bačáková, and Petr Kubový \\ Faculty of Physical Education and Sport, Charles University, Prague, Czech Republic
}

Copyright: (C) 2016 V. Hojka et al. This is an open access article licensed under the Creative Commons Attribution License (http://creativecommons.org/licenses/by/4.0/).

\begin{abstract}
Background: Many sport activities are a sequence of jumps (running, jumping, hurdling etc.). Each jump flight phase is the result of the execution of the previous support phase. Objective: The goal of the research was to identify differences in adjustment of the support lower limb and differences in take-off kinematics in specific take-off movement task. Methods: 14 male athletes $(22.6 \pm 4.4$ years; $182.4 \pm 5.3 \mathrm{~cm} ; 74.7 \pm 6.2 \mathrm{~kg})$ took part in a laboratory experiment. Each athlete performed five different take-off movements (running, acceleration running - second step, long jump take-off, high jump take-off and take-off to the hurdle). System Qualisys was used to analyze the kinematics of the support limb. Dynamics of the support phase was monitored via force plate. ANOVA and Bonferroni post-hoc test were used to measure the significance of the differences between different take off tasks. Results: Dynamic characteristic showed significant differences in take-off $(p<.001)$. This variability is caused by differences in kinematic parameters at the instant of touch-down, minimum joint angles and take-off. The most important finding was different variability in range of motion in eccentric or concentric phases of each jump. Vertically orientated jumps are terminated in a higher degree of extension. Horizontal take-off types are characterized by the highest ranges of motion especially in the ankle joint. Conclusions: The support lower limb compliance is adjusted to the required task, which is related to lower limb kinematics during the support phase. High range of motion in each joint refers to more compliant adjustment of the joint.
\end{abstract}

Keywords: jumping, dynamics, biomechanics, variability, stiffness

\section{Introduction}

Many sport activities contain various situations, which require specific take-off skills. Not only track and field events, but also sport games (basketball, handball, football, etc.) are well-known for their specific requirements on the jumping behavior of an athlete. Jump shots, rebounding, lay-ups, dunks; each basketball activity demands different solution of the jumping task (Abdelkrim, El Fazaa, \& El Ati, 2007). Similarly, different target of the take-off is obvious in comparison of shooting from the wing, pivot or backcourt position in handball (Chaouachi et al., 2009). As the situation that affects the jumping is more complicated in sport games, we concentrated on jumps related to specific a track and field event. All jumps belong to group of

\footnotetext{
* Address for correspondence: Vladimír Hojka, Track and Field Department, Faculty of Physical Education and Sport, Charles University, José Martího 31, 16252 Prague 6, Czech Republic. E-mail: hojka@ftvs.cuni.cz
}

rapid, ballistic movement, which use only feed forward control. The execution of the movement is finished before any sensory information may subsequently trigger a specific motor command. Therefore proper adjustment of the human body is a crucial factor to successful execution of a take-off (Striemer, Yukovsky, \& Goodale, 2010).

Running is a typical activity consisting of takeoffs. Running is a sequence of running strides, which consist of the alternation of the support phase and the flight phase (Bosch \& Klomp, 2004; Hay \& Reid, 1988). The ground reaction force causes the changes of the momentum of the athlete's body during the support phase. An athlete has no chance to change his momentum during the flight phase, but can prepare for the following support phase. The outputs of the support phase serve also as the inputs for the flight phase. Graham and Harrison (2006) presented the deterministic model of sprint. Its part could be modified to other jumping activities. The flight trajectory of center of mass (COM) is determined by its height and 
velocity at the instant of take-off and angle of take-off. These parameters are results of the lower limb activity throughout the take-off preparation and execution.

The take-off preparation seems to be crucial for the following execution of take-off. Many jumps utilize the elasticity of the musculoskeletal system of human body. The major role in elasticity adjustment is played by the antagonist co-activation, which define the rotation stiffness of each joint (Kellis, Arabatzi, \& Papadopoulos, 2003; Kyröläinen, Avela, \& Komi, 2005; Seyfarth, Bobbert, \& Blickhan, 2001; Seyfarth, Gunther, \& Blickhan, 2001; Yakovenko, Gritsenko, \& Prochazka, 2004).

Effective sprinting requires short contact time (Ciacci, Di Michele, \& Merni, 2010; Čoh, Peharec, Bačić, \& Kampmiller, 2009), which is associated to high level of ankle joint stiffness defined by triceps surae and tibialis anterior muscles. The acceleration phase needs more concentric explosive strength compared to maximum velocity phase. Therefore the goal of the movement is to produce high acceleration in short contact time, which requires higher muscle activation (Kugler \& Janshen, 2010; Roberts, 2006).

Long jump is a discipline, which is typical with high impact forces and short contact times during take-off (Hay, Thorson, \& Kippenhan, 1999; Mendoza, Nixdorf, Isele, \& Günther, 2009; Seyfarth, Friedrichs, Wank, \& Blickhan, 1999). This arises from the necessity to produce high vertical velocity with minimum losses of horizontal velocity. The loss of horizontal velocity highly correlates $(r=.93)$ with the gain of vertical velocity in the long jump (Graham-Smith \& Lees, 2005). Long jump take-off requires a high level of ankle and knee stiffness prior to touch-down (Panoutsakopoulos \& Kollias, 2009).

Various attitudes are described in the high jump, which may produce the same results. Two basic strategies are distinguished in the high jump - power flop and speed flop (Dapena, 1996, 1997; Dapena, McDonald, \& Cappaert, 1990). Power flop is typical for taller athletes with less reactive strength capacity. It can be recognized by longer take-off duration, more massive swing of free segments (swing leg or arms), slower approach and higher level of knee flexion of the support leg during take-off (Isolehto, Virmavirta, Kyröläinen, \& Komi, 2007; Ritzdorf, 2009).

The optimization criterion of the hurdle take-off is to minimize flight time and avoid the collision with the hurdle. Therefore it needs to be kept flat, without generating too high of a vertical force-impulse (Coh, Jošt, \& Škof, 2000; McDonald \& Dapena, 1991; Mero $\&$ Luhtanen, 1986; Tidow, 1991). Height of the COM at the instant of take-off is in increased importance, which is realized by a higher degree of support leg extension in ankle, knee and hip joint.
The aim of the paper is to provide an explanation, how the different take-off objectives are related to timecourse kinematic of the ankle and knee joint of the support leg. The existence of differences in the angles in touch-down, maximum knee and ankle flexion and angles at the instant of take-off as well as differences in eccentric and concentric range of motion during different types of take-off serves as a hypothesis of our study.

\section{Methods}

The independent variable of our experiment is the type of take-off (running, acceleration running, long jump, high jump, hurdle clearance). The dependent variables are the angles of knee and ankle joint at the instant of touch-down, at maximum knee and ankle flexion, and angles at the instant of take-off. The other dependent variables are the duration of the take-off and total force impulse generated during take-off phase (horizontal and vertical components).

\section{Participants}

Fourteen active decathletes (male; $22.6 \pm 4.4$ years; $182.4 \pm 5.3 \mathrm{~cm} ; 74.7 \pm 6.2 \mathrm{~kg}$ ), who have experience with different types of take-off (personal best result in decathlon ranged between 5652 and 6743 points) took part in the laboratory experiment. All participants were first verbally informed about the goals of the study, warm-up protocol, laboratory procedures and possible risks of the study. Subjects were free to withdraw from experiment at any moment. Those, who voluntarily agreed, were asked to sign written consent. The research was approved by the Ethical Committee of the Faculty of the Physical Education and Sport, Charles University in Prague under reference number 0149/2010.

\section{Procedures}

All athletes performed five different types of takeoff. The warm-up protocol preceded the laboratory measurement. It consisted of 6 min jogging, dynamic stretching exercises and specific running and jumping drills. Total warm-up duration was between 16-20 minutes. A few unmeasured trials were performed before each analyzed jump, to execute prescribed take-offs naturally. The analyzed movements were following: running at moderate speed $\left(4-5 \mathrm{~m} \cdot \mathrm{s}^{-1}\right)$; acceleration running - second step after leaving the blocks; long jump take-off with 6 steps approach; high jump take-off with 6 steps approach; hurdle take-off $(91.4 \mathrm{~cm})$ with 6 steps approach with high knee lifts. The length of the approach was limited by the area of the laboratory room. Subjects performed two trials of each take-off 
type, but only one was analyzed - the one, that better satisfied the take-off objectives.

Each take-off was performed on the force plate embedded on the floor (Kistler 9281, Kistler Group, Winterthur, Switzerland). Sample rate of the plate was $1000 \mathrm{~Hz}$. The take-off execution was permitted to latter analysis, if it was performed naturally, and the whole foot was placed on the force plate. The instant of touch-down was defined as the first sample with vertical force component exceeding threshold 5 N. Similarly, the instant of take-off was defined by the sample, when vertical force fell below the threshold $5 \mathrm{~N}$.

The changes of velocity components $\left(\mathrm{Dv}_{h}\right.$ and $\left.\mathrm{D} v_{v}\right)$ were calculated as a ratio of the force impulses and the mass $m$ of the athlete by the formulas:

$$
\Delta v_{h}=\frac{\int_{t_{d}}^{t_{o}} F_{x} d t}{m} ; \Delta v_{v}=\frac{\int_{t_{d}}^{t_{o}}\left(F_{y} d t-m g\right) d t}{m}
$$

where $F_{x}$ (resp. $F_{y}$ ) denotes horizontal anterior-posterior (resp. vertical) component of the ground reaction force, $t_{d}$ is the instant of touch-down and $t_{o}$ is the instant of the take-off, $g$ is the gravitational acceleration.

Qualisys system (Qualisys AB, Goteborg, Sweden) was used to determine kinematic parameters of the support lower limb. Six cameras were placed to monitor calibrated area $3 \times 2 \times 1.5$ meters. The sample rate was $200 \mathrm{~Hz}$. System was automatically triggered with the force plate. The force plate was located in the middle of the area. Reflex markers were placed on the subject's lower limb (Figure 1). Two markers defined each segment (foot, shank and thigh). The marker's coordinates were calculated, if the marker was at least visible by two cameras. The markers were placed on the palpated formation of each segment.

The angle in ankle joint was defined as the angle of foot vector (heel to toe orientation) and shank vector (ankle to knee orientation). Knee joint angle was defined as the angle of thigh (knee to hip) vector and shank vector (knee to ankle). Qualisys Track Manager Software was used to calculate marker's coordinates at each instant.

The marker's coordinates were exported to MATLAB (MathWorks, Inc., Natick, MA, USA) and used for further calculation.

The eccentric phase in both joints was defined as the time interval from the instant of touch-down to maximum joint flexion. Concentric phase started at the instant of maximum joint flexion and terminated at the instant of take-off.

\section{Statistical processing}

Analysis of variance (ANOVA) was used to evaluate the statistical significance of the differences between

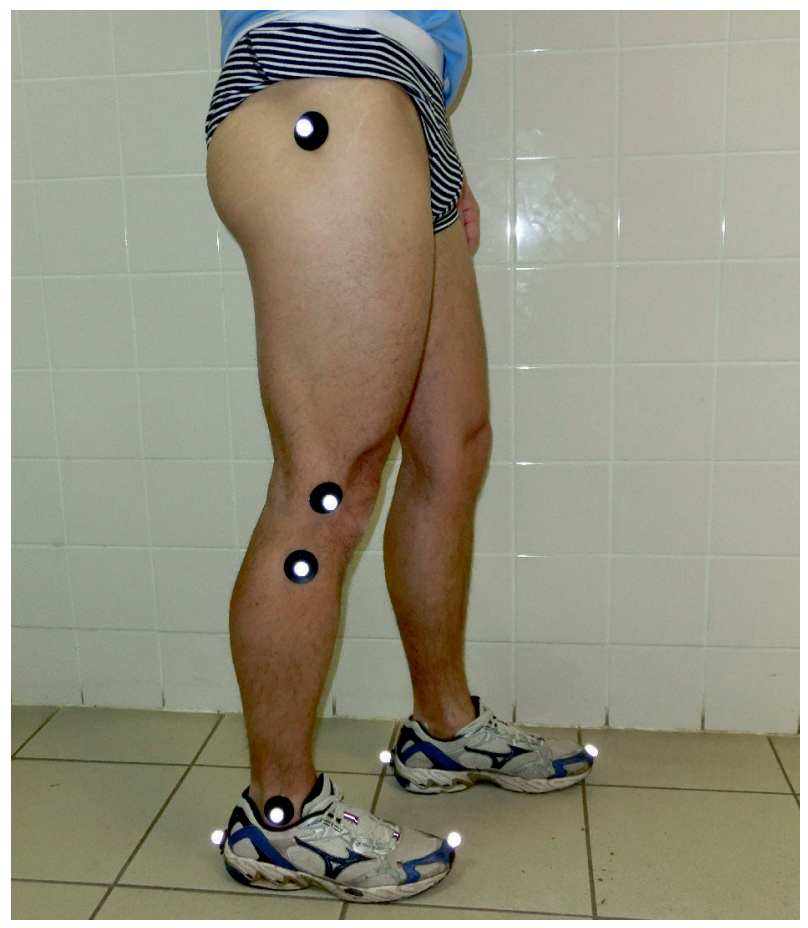

Figure 1. Qualisys marker placement. Each segment vector is defined by pair of markers - foot by the toe and heel markers; shank markers were placed on malleolus lateralis and lateral condyle of tibia; thigh segment was defined by markers placed on trochanter major and lateral condyle of femur.

groups of take-off. Bonferroni test served as a post-hoc test. The level of significance was set to 0.05 . Levene test of homoscedasticity and Kolmogorov-Smirnov test of distribution normality were performed prior to ANOVA. IBM SPSS (Version 22; IBM, Armonk, NY, USA) software was used for the statistical analysis of the results.

\section{Results}

The support phase characteristics described by the changes of horizontal and vertical velocity and its duration exhibited clearly different parameters in each jump $(p<.001)$. The post-hoc analysis showed that all types of jump are unique in terms of horizontal and vertical velocity changes $(p<.001)$. However, similarities were observed in certain types of jumps in duration. Dynamic characteristics of the support phase are presented in Table 1.

The duration of eccentric and concentric phases of each type of the jump is displayed in Table 2. No differences between jumps were found in the duration of eccentric (resp. concentric) phase in the ankle joint of the support leg. However, variability was present in 
Table 1

Changes of velocity and duration during take-off phase

\begin{tabular}{lccc}
\hline & $\mathrm{v}_{\mathrm{h}}\left(\mathrm{m} \cdot \mathrm{s}^{-1}\right)$ & $\mathrm{v}_{\mathrm{v}}\left(\mathrm{m} \cdot \mathrm{s}^{-1}\right)$ & Duration $(\mathrm{s})$ \\
\hline Running & $0.11 \pm 0.08^{* 2,3,4,5}$ & $1.52 \pm 0.08^{* 2,3,4,5}$ & $0.157 \pm 0.013^{* 2,3,4,5}$ \\
Acceleration running & $0.81 \pm 0.08^{* 1,3,4,5}$ & $0.74 \pm 0.16^{* 1,3,4,5}$ & $0.191 \pm 0.021^{* 1}$ \\
Long jump & $-1.06 \pm 0.2{ }^{* 1,2,4,5}$ & $3.24 \pm 0.27^{* 1,2,4,5}$ & $0.176 \pm 0.011^{* 1,4}$ \\
High jump & $-1.79 \pm 0.22^{* 1,2,3,5}$ & $3.62 \pm 0.19^{* 1,2,3,5}$ & $0.202 \pm 0.011^{* 1,3,5}$ \\
Hurdle & $-0.68 \pm 0.16^{* 1,2,3,4}$ & $2.48 \pm 0.31^{* 1,2,3,4}$ & $0.177 \pm 0.019^{* 1,4}$ \\
\hline
\end{tabular}

Note. *significantly different $(p<.05)$ from: 1 - running, 2 - acceleration running, 3 - long jump,

4 - high jump, 5 - hurdle.

Table 2

Eccentric and concentric phase durations (presented as mean $\pm S D$ in seconds) in ankle and knee joints

\begin{tabular}{|c|c|c|c|c|}
\hline & \multicolumn{2}{|c|}{ Ankle joint } & \multicolumn{2}{|c|}{ Knee joint } \\
\hline & Eccentric & Concentric & Eccentric & Concentric \\
\hline Running & $0.085 \pm 0.010$ & $0.072 \pm 0.009$ & $0.073 \pm 0.011^{* 2,4}$ & $0.084 \pm 0.009 * 2$ \\
\hline Acceleration running & $0.089 \pm 0.029$ & $0.102 \pm 0.022$ & $0.014 \pm 0.035^{* 1,3,4,5}$ & $0.177 \pm 0.029^{* 1,3,4,5}$ \\
\hline Long jump & $0.086 \pm 0.038$ & $0.089 \pm 0.042$ & $0.077 \pm 0.024^{* 2,4}$ & $0.099 \pm 0.021{ }^{* 2}$ \\
\hline High jump & $0.088 \pm 0.063$ & $0.115 \pm 0.065$ & $0.113 \pm 0.015^{* 1,2,3,5}$ & $0.090 \pm 0.015^{* 2}$ \\
\hline Hurdle & $0.103 \pm 0.013$ & $0.074 \pm 0.013$ & $0.078 \pm 0.014^{* 2,4}$ & $0.100 \pm 0.015^{* 2}$ \\
\hline
\end{tabular}

Note. *significantly different $(p<.05)$ from: 1 - running, 2 - acceleration running, 3 - long jump, 4 - high jump, 5 - hurdle

the knee joint. The eccentric phase during acceleration running was short compared with others, and the eccentric phase during high jump was the longest. Only the concentric phase of the knee in acceleration running exhibited significantly longer duration than other types of jumps.

The values of angles in ankle and knee joint during the support phase (touch-down, minimum and takeoff) are displayed in Figure 2.

Running at moderate velocity is typical with its high range of motion in eccentric and concentric phase during the support phase (Figures 3 and 4). Acceleration running is the most concentric type of take-off in both joints. On the other side high jump take-off produces the highest vertical velocity and performs the smallest range of motion in the ankle joint from all types of jump (Figure 3).

Acceleration running take-off is unique in comparison with the other types of the jumps, because its eccentric phase is very short or there was no eccentric phase presented. The rest of the jumps did not show significant differences in eccentric range of motion in knee joint (Figure 4). Smallest concentric range of motion is performed in running support phase. High concentric range of motion was found in acceleration running and high jump, while long jump and hurdle take-off were significantly different from one of the extremes.

\section{Discussion}

Various types of take-off produced different support phase characteristics. The changes of velocity components alongside with the support phase duration were clearly different between take-off types. However, these differences in the dynamics are caused by more similar time-courses of the lower limb joints kinematics.

The most concentric type of take-off was acceleration running. Both joints (ankle and knee) performed concentric contraction in most of the support phase duration, which is in agreement with other studies (Čoh, Peharec, \& Bačić, 2007; Čoh et al., 2009; Kugler \& Janshen, 2010; Slawinski et al., 2010). For this purpose, both joints were adjusted to highest rate of flexion at the instant of touch-down. As there are minimum requirements for reactive strength capacity in acceleration running, athlete should concentrate on high concentric force exertion on the ground with a short contact time.

Support phase in running was the most compliant among the take-offs. It exhibited high range of motion in eccentric and concentric phases. Both phases took approximately the same duration. The explanation for the compliance rises from the dynamics of the support phase. Muscles acting in both joints should be preactivated, but the impact forces are not high in comparison with other types of the jump. Stable running 
a) ankle joint touchdown

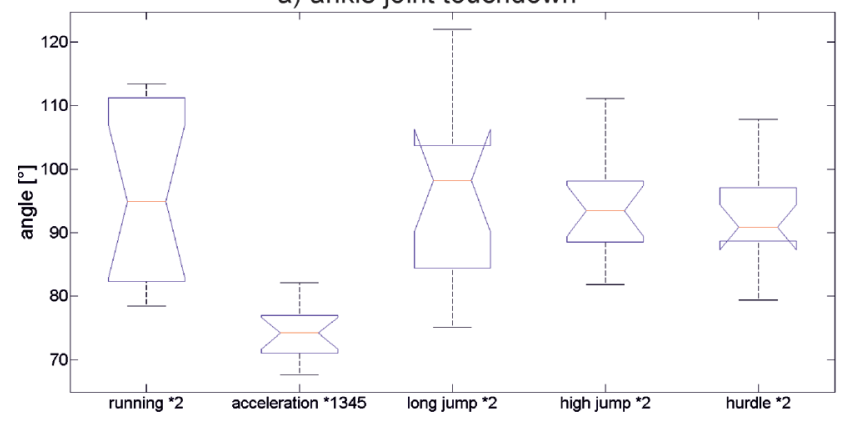

c) minimum ankle joint angle

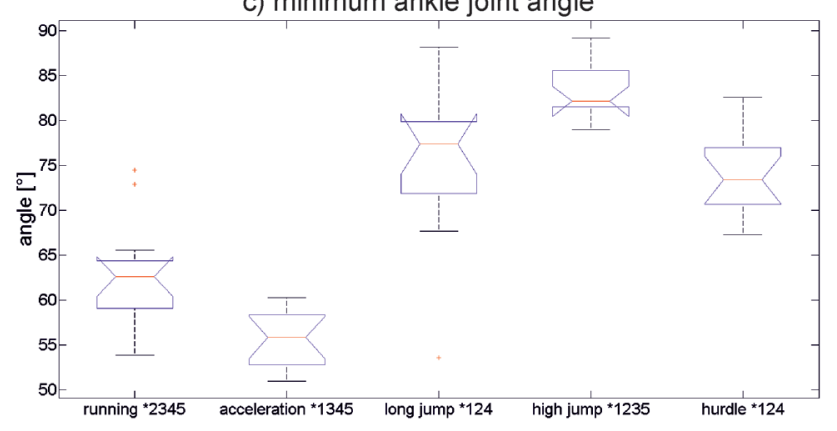

e) ankle joint take-off

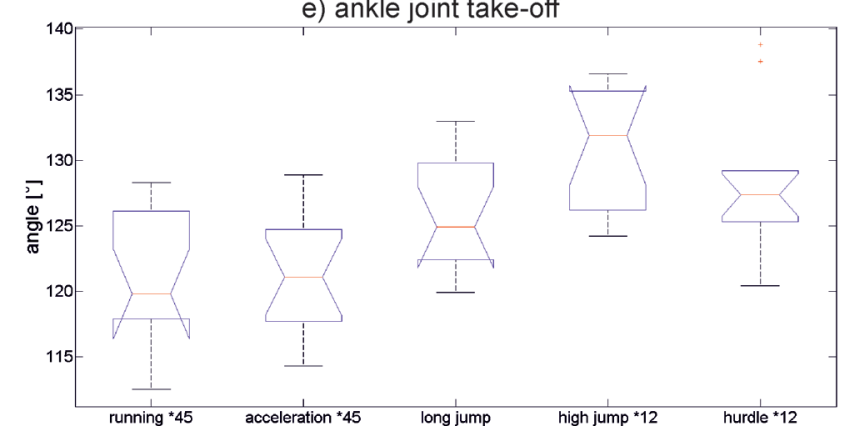

b) knee joint touchdown

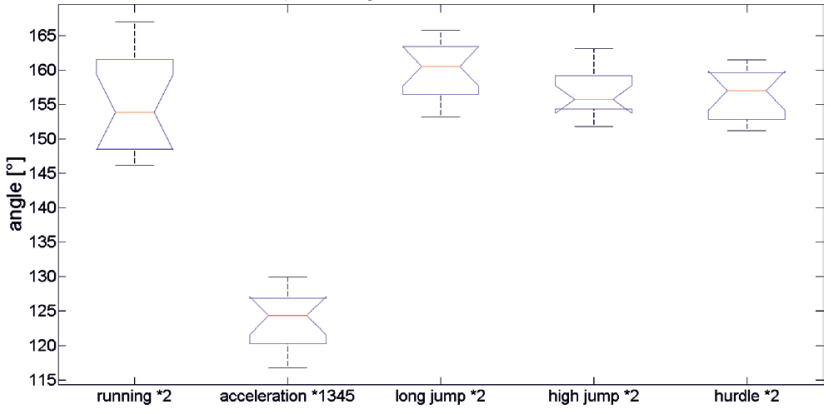

d) minimum knee joint angle

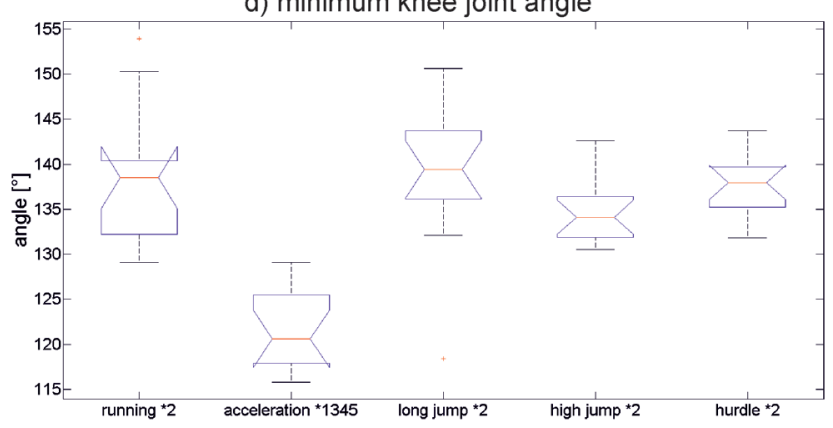

f) knee joint take-off

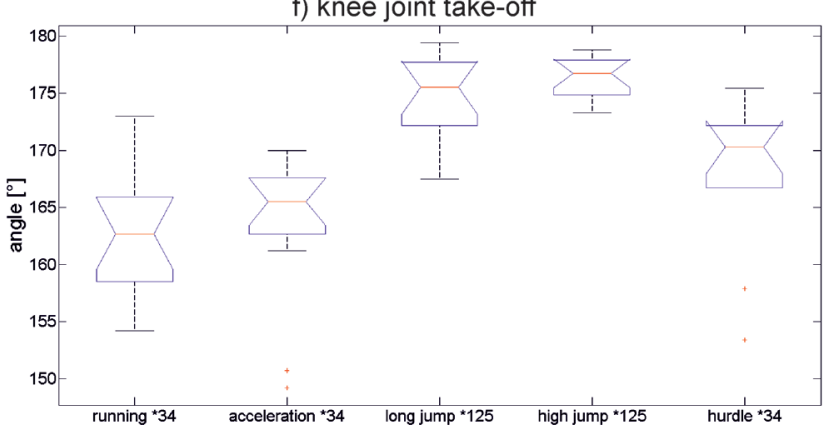

Figure 2. Angles in the ankle and knee joint during support phase. Box graphs display the range values of the various take-off types at the instant of touch-down (a, b), maximum joint flexion (c, d) and at the instant of take-off (e, f). Left column belongs to characteristic of ankle joint angles, right column displays knee joint characteristics. Significant differences between types of take-off are denoted with * followingly: *significantly different $(p<.05)$ from: 1 - running, 2 - acceleration running, 3 - long jump, 4 - high jump, 5 - hurdle.

a) eccentric range of motion - ankle

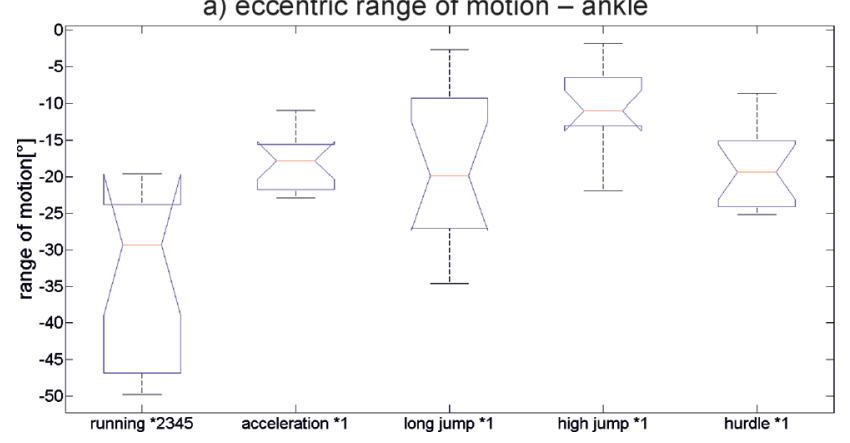

b) concentric range of motion - ankle

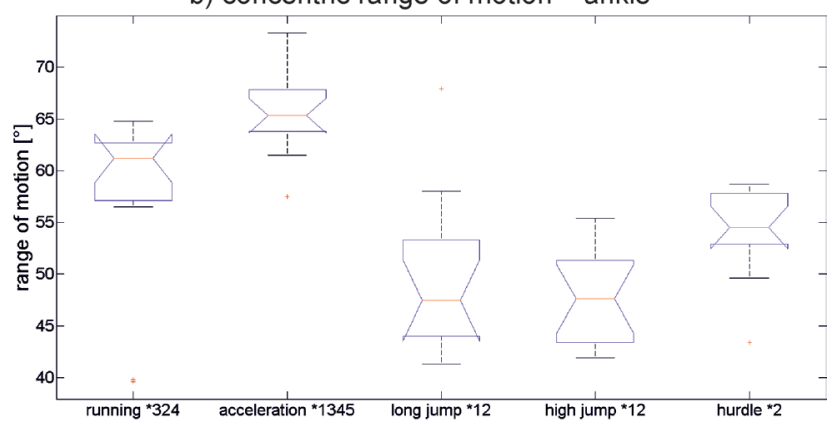

Figure 3. Eccentric (a) and concentric (b) range of motion in the ankle joint. Box graphs display the distribution of values of each type of the jump. Significant differences $(p<.05)$ are denoted with * and numbered with relation to the take-off type: 1 - running, 2 - acceleration running, 3 - long jump, 4 - high jump, 5 - hurdle. 
a) eccentric range of motion - knee

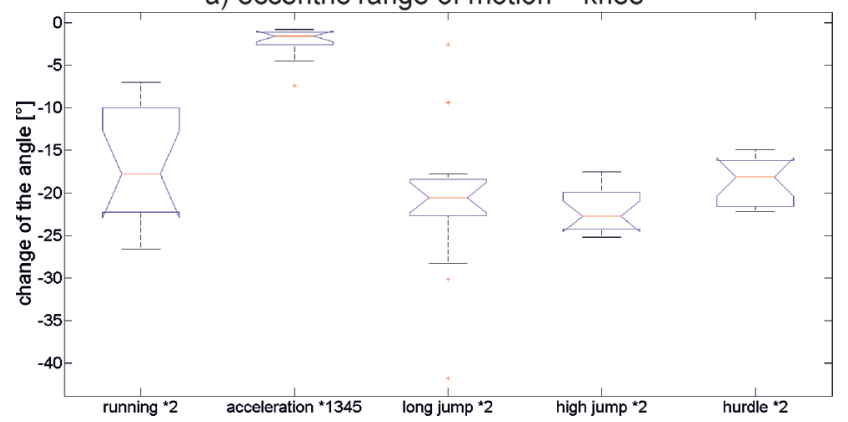

b) concentric range of motion - knee

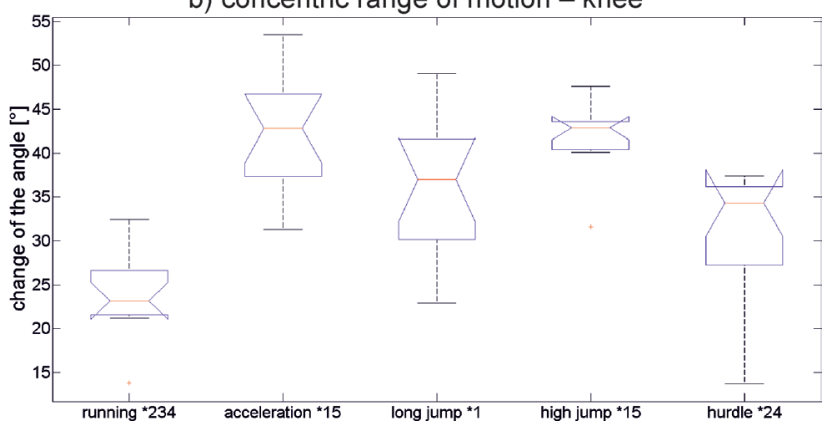

Figure 4. Eccentric (a) and concentric (b) range of motion in the knee joint. Box graphs display the distribution of values of each type of the jump. Significant differences $(p<.05)$ are denoted with * and numbered with relation to the take-off type: 1 - running, 2 - acceleration running, 3 - long jump, 4 - high jump, 5 - hurdle.

requires moderate stiffness adjustment of both joints to minimize energy cost of the task. This changes dramatically with increased speed. Especially, the importance of ankle joint stiffness is rising with increasing speed (Arampatzis, Brüggemann, \& Metzler, 1999; Kyrolainen et al., 2005; McMahon \& Cheng, 1990; Mero \& Komi, 1986), which is primarily responsible for shortening the contact time. The athletes in our study run at speed approximately $5 \mathrm{~m} \cdot \mathrm{s}^{-1}$, which corresponds to middle distance running performance (3000 meters in 10 minutes). The support phase duration of our subjects was reasonably longer $(0.157 \pm 0.013 \mathrm{~s})$ than achieved by sprinters under $11.00 \mathrm{~s}$ in 100 meters (0.080-0.100 s) reported by Mero, Komi, and Gregor (1992) or Coh et al. (2009). The athletes were limited by the environment of the lab, which did not allow safe running at higher velocities due to limited space.

Hurdle take-off is typical with keeping the hurdle clearance flat without producing high vertical velocity and without losing horizontal velocity. Typical in the kinematics was longer eccentric phase duration in the ankle joint. The reason for such behavior is controlled compliance of the ankle joint, usually coupled with high position of the hurdler achieved by stepping on the forefoot (Čoh et al., 2011; Tidow, 1991). Compared with other take-offs, which produce higher vertical velocity, hurdle take-off exhibit higher range of concentric motion in ankle joint and smaller range of motion in knee. However, the second (concentric range of motion in knee) did not match statistical significance level of difference. This may be caused by the heterogeneity of the athlete's execution of hurdle take-off, which is associated with highest SD in vertical velocity production among all of the jump types. While some of the athletes performed the jump by attacking the hurdle, the others' execution was more like an "obstacle jump over”, even though subjects had enough experience with hurdle clearance.
The high jump key characteristic was a high range of motion in the knee joint, which helps to generate large amount of vertical momentum. Kinematic parameters of our athletes were similar to those reported earlier (Čoh \& Novak, 2002; Dapena et al., 1990; Isolehto et al., 2007). However, approach speed of our subjects was lower due to laboratory space constraints, so joint-torque characteristics of our athletes and top athletes should be different. Some athletes did not have an eccentric phase in the ankle, which may be explained by well executed lock-down foot placement at the instant of touch-down. This phenomenon caused high SD of eccentric phase duration and caused the population heterogeneity consequently. As the height of the COM at the instant of take-off serves as the secondary criterion of the high jump, athletes achieved the highest degree of extension in both joints to raise their COM.

Take-off in the long jump showed high variability in the degree of knee flexion. Moderate speed of approach should explain this variability sufficiently, while full speed approach does not allow such range of motion in knee (Graham-Smith \& Lees, 2005; Hay, 2000; Seyfarth, Friedrichs, Wank, \& Blickhan, 1999). Moderate speed of approach caused, the long jump execution was similar to high jump take-off in ranges of motion in ankle, knee and also in time-course of the angles in each joint, but with higher variability in some of the parameters.

The limits of the study are the following - six step approaches did not allow analysis of competition-like performance of each take-off. Therefore, an alternative strategy was identified in some cases of the take-off (especially long jump and hurdle). More compliant joint adjustment was presented in take-offs, to clear the hurdle in controlled speed or to jump higher in case of the long jump.

Another important aspect is the lead leg action. Its importance rises in high jump and hurdle take-off, 
where it directly influences dynamic parameters of the take-off, especially take-off duration and changes in velocity consequently.

\section{Conclusion}

The existence of differences in the angles at the instant of touch-down, maximum joint flexion and take off was confirmed. Similarly, significant differences were observed in eccentric and concentric ranges of motion only in knee joint during various types of take-off.

Basic insight into jumping differentiation was provided and results show obvious tendencies in each type of take-off. The horizontally orientated jumps (acceleration running, running) are typical with high concentric range of motion in the ankle joint. The emphasized propulsion phase of these jumps provides sufficient explanation. This range of motion decreases, while the jump is orientated more vertically. The vertically orientated take-offs were terminated at higher rate of knee and ankle extension. This finding corresponds to stiffer joint adjustment in long and high jump take-off.

\section{Acknowledgment}

Research was supported by grant PRVOUK P38.

\section{Conflict of interest}

There were no conflicts of interest.

\section{References}

Abdelkrim, N. B., El Fazaa, S., \& El Ati, J. (2007). Timemotion analysis and physiological data of elite under-19year-old basketball players during competition. British Journal of Sports Medicine, 41, 69-75.

Arampatzis, A., Brüggemann, G.-P., \& Metzler, V. (1999). The effect of speed on leg stiffness and joint kinetics in human running. Journal of Biomechanics, 32, 1349-1353.

Bosch, F., \& Klomp, R. (2004). Running: Biomechanics and exercise physiology in practice. New York, NY: Churchill Livingstone.

Chaouachi, A., Brughelli, M., Levin, G., Boudhina, N. B. B., Cronin, J., \& Chamari, K. (2009). Anthropometric, physiological and performance characteristics of elite teamhandball players. Journal of Sports Sciences, 27, 151-157.

Ciacci, S., Di Michele, R., \& Merni, F. (2010). Kinematic analysis of the braking and propulsion phases during the support time in sprint running. Gait \& Posture, 31, 209-212.
Coh, M., Jošt, B., \& Škof, B. (2000). Kinematic and dynamic analysis of hurdle clearance technique. Paper presented at the 18th International Symposium on Biomechanics in Sports, Hong Kong, China.

Čoh, M., \& Novak, J. (2002). Performance model of female high jumpers applied to the space of kinematic parameters. In M. Coh (Ed.), Application of biomechanics in track and field (pp. 135-142). Ljubljana, Slovenia: University of Ljubljana.

Čoh, M., Peharec, S., \& Bačić, P. (2007). Analiza kinematičnih, dinamičnih in elektromiografskih parametrov štarta. [Analysis of kinematic, dynamic and electromyographic start parameters]. Šport: Revija Za Teoretična in Praktična Vprašanja Športa, 55(2), 51-56.

Čoh, M., Peharec, S., Bačić, P., \& Kampmiller, T. (2009). Dynamic factors and electromyographic activity in a sprint start. Biology of Sport, 26, 137-147.

Dapena, J. (1996). A biomechanical scientific support program for high jumpers. Paper presented at the 14th Symposium on Biomechanics in Sports, Madeira, Portugal.

Dapena, J. (1997). A closer look at the shape of the highjump run-up. Track Coach, 138, 4406-4411.

Dapena, J., McDonald, C., \& Cappaert, J. (1990). A regression-analysis of high jumping technique. International Journal of Sport Biomechanics, 6, 246-261.

Graham, D., \& Harrison, A. J. (2006). A biomechanical investigation of the application of schema theory in the sprint start. Paper presented at the 24th International Symposium on Biomechanics in Sport, Salzburg, Austria.

Graham-Smith, P., \& Lees, A. (2005). A three-dimensional kinematic analysis of the long jump take-off. Journal of Sports Sciences, 23, 891-903.

Hay, J. G. (2000). Biomechanics of the long jump: Some wider applications. Retrieved from http://www.sp.uconn. edu/ yian/hay.htm

Hay, J. G., \& Reid, J. G. (1988). Anatomy, mechanics, and human motion (2nd ed.). Englewood Cliffs, NJ: Prentice Hall.

Hay, J. G., Thorson, E. M., \& Kippenhan, B. C. (1999). Changes in muscle-tendon length during the take-off of a running long jump. Journal of Sports Sciences, 17, 159-172.

Isolehto, J., Virmavirta, M., Kyröläinen, H., \& Komi, P. V. (2007). Biomechanical analysis of the high jump. Retrieved from: http://www.portugalsaltos.com/site/Publicacoes_ files/38219.pdf

Kellis, E., Arabatzi, F., \& Papadopoulos, C. (2003). Muscle co-activation around the knee in drop jumping using the co-contraction index. Journal of Electromyography and Kinesiology, 13, 229-238.

Kugler, F., \& Janshen, L. (2010). Body position determines propulsive forces in accelerated running. Journal of Biomechanics, 43, 343-348.

Kyröläinen, H., Avela, J., \& Komi, P. V. (2005). Changes in muscle activity with increasing running speed. Journal of Sports Sciences, 23, 1101-1109.

McDonald, C., \& Dapena, J. (1991). Linear kinematics of the men's 110-m and women's 100-m hurdles races. Medicine \& Science in Sports \& Exercise, 23, 1382-1391.

McMahon, T. A., \& Cheng, G. C. (1990). The mechanics of running: how does stiffness couple with speed? Journal of Biomechanics, 23(Suppl. 1), 65-78. 
Mendoza, L., Nixdorf, E., Isele, R., \& Günther, C. (2009). Biomechanical analysis of the long jump men final. In $\mathrm{H}$. Hommel (Ed.), Scientific research project: Biomechanical analyses at the Berlin 2009 12th IAAF World Championships in Athletics. Final Report. Darmstadt, Germany: Deutsche Leichtathletik-Verband.

Mero, A., \& Komi, P. (1986). Force-, EMG-, and elasticityvelocity relationships at submaximal, maximal and supramaximal running speeds in sprinters. European Journal of Applied Physiology and Occupational Physiology, 55, 553-561.

Mero, A., Komi, P. V., \& Gregor, R. J. (1992). Biomechanics of sprint running: A review. Sports Medicine, 13, 376-392.

Mero, A., \& Luhtanen, P. (1986). Biomechanische Untersuchung des Hürdenlaufs während der Weltmeisterschaften in Helsinki [Biomechanical investigations of sprint hurdles during the World Championships in Athletics in Helsinki]. Leistungssport, 1, 42-43.

Panoutsakopoulos, V., \& Kollias, I. A. (2009). Biomechanical analysis of the last strides, the touchdown and the takeoff of top Greek male and female long jumpers. Hellenic Journal of Physical Education \& Sport Science, 29, 200-218.

Ritzdorf, W. (2009). Approaches to technique and technical training in the high jump. New Studies in Athletics, 24(3), $31-34$
Roberts, T. J. (2006). Integrated muscle-tendon function during running accelerations. Journal of Biomechanics, 39(Suppl. 1), S360.

Seyfarth, A., Bobbert, M. F., \& Blickhan, R. (2001). The origin of spring-like leg behaviour in long jump. Jena, Germany: Friedrich-Schiller-University.

Seyfarth, A., Friedrichs, A., Wank, V., \& Blickhan, R. (1999). Dynamics of the long jump. Journal of Biomechanics, 32, 1259-1267.

Seyfarth, A., Gunther, M., \& Blickhan, R. (2001). Stable operation of an elastic three-segment leg. Biological Cybernetics, 84, 365-382.

Slawinski, J., Bonnefoy, A., Ontanon, G., Leveque, J. M., Miller, C., Riquet, A., ... Dumas, R. (2010). Segment-interaction in sprint start: Analysis of 3D angular velocity and kinetic energy in elite sprinters. Journal of Biomechanics, 43, 1494-1502.

Striemer, C. L., Yukovsky, J., \& Goodale, M. A. (2010). Can intention override the "automatic pilot"? Experimental Brain Research, 202, 623-632.

Tidow, G. (1991). Model technique analysis sheets for the hurdles. Part VII: High hurdles. New Studies in Athletics, 6(2), 51-66.

Yakovenko, S., Gritsenko, V., \& Prochazka, A. (2004). Contribution of stretch reflexes to locomotor control: A modeling study. Biological Cybernetics, 90, 146-155. 